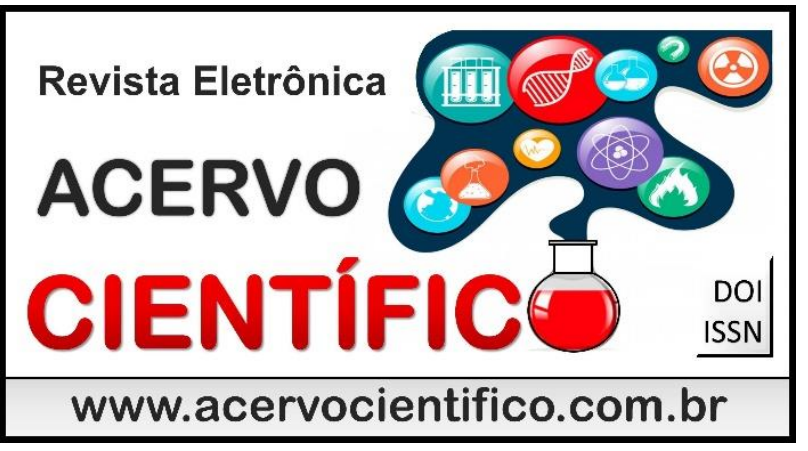

ARTIGO DE REVISÃO

Recebido em: 11/2018

Aceito em: $12 / 2018$

Publicado em: 1/2019

\title{
A importância do ensino de história e cultura afro-brasileira no ensino fundamental
}

The importance of teaching Afro-Brazilian history and culture in elementary school

La importancia de la enseñanza de historia y cultura afro-brasileña en la enseñanza fundamental

Leila Gonçalves Silva Araújo ${ }^{1 *}$, Alessander Freitas do Amaral ${ }^{1}$

\begin{abstract}
Resumo: A História e cultura afro-brasileira tornou-se um dos conteúdos cujo ensino é fundamental. Por meio de leis, a inclusão deste conteúdo se tornou obrigatório de modo interdisciplinar e passou a fazer parte dos livros didáticos. A contribuição dos africanos para a formação da cultura no Brasil abrange diversas áreas, desde músicas e danças até a culinária. O presente artigo buscou evidenciar a implementação do estudo da cultura e história afro-brasileira nos anos iniciais do ensino fundamental, demonstrando de que forma tal cultura está presente e influi nos costumes brasileiros. Além disso, foi analisada a importância deste ensino para a valorização do negro e a diminuição da prática do racismo em sala de aula. Este trabalho foi realizado por meio de revisão literária narrativa conceitual, buscando fontes em livros, artigos científicos, dissertação, jornais e revistas, de tal maneira que foram feitas as buscas em bibliotecas, bancos de dados e em sites da internet. Também foram realizadas consultas à Legislação Educacional Brasileira. Concluímos, então, que apesar de diversas conquistas para inclusão de tais conteúdos supracitados na educação, a luta para igualdade afro-brasileira ainda não acabou.
\end{abstract}

Palavras-chaves: Cultura afro-brasileira; História afro-brasileira; Educação.

\begin{abstract}
Afro-Brazilian culture has become one of the contents whose teaching is fundamental. By means of laws, the inclusion of this content became compulsory in an interdisciplinary way and became part of the textbooks. The contribution of Africans to the formation of culture in Brazil covers diverse areas, from songs and dances to cooking. The present study sought to highlight the implementation of the study of Afro-Brazilian culture and history in the initial years of elementary education, demonstrating how this culture is present and influences Brazilian customs. In addition, the importance of this teaching for the valorization of the black and the reduction of the practice of racism in the classroom was analyzed. The present study was carried out through literary review conceptual narrative, searching for sources in books, scientific articles, dissertation, newspapers and magazines, in such a way that searches were ade in libraries and databases on internet sites. Consultations were also held with the Brazilian Educational Legislation. We conclude that despite several achievements to include such content in education, the struggle for Afro-Brazilian equality has not yet ended.
\end{abstract}

Key-words: Afro-Brazilian culture; Afro-Brazilian History; Education.

\footnotetext{
${ }^{1}$ Faculdade Patos de Minas (FPM), Minas Gerais. *E-mail: leilagoncalvesaraujo@hotmail.com
} 
Resumen: La historia y cultura afro-brasileña se ha convertido en uno de los contenidos cuya enseñanza es fundamental. Por medio de leyes, la inclusión de este contenido se hizo obligatorio de modo interdisciplinario y pasó a formar parte de los libros didácticos. La contribución de los africanos para la formación de la cultura en Brasil abarca diversas áreas, desde músicas y danzas hasta la culinaria. El presente artículo buscó evidenciar la implementación del estudio de la cultura e historia afro-brasileña en los años iniciales de la enseñanza fundamental, demostrando de qué forma tal cultura está presente e influye en las costumbres brasileñas. Además, se analizó la importancia de esta enseñanza para la valorización del negro y la disminución de la práctica del racismo en el aula. Este trabajo fue realizado por medio de revisión literaria narrativa conceptual, buscando fuentes en libros, artículos científicos, disertación, periódicos y revistas, de tal manera que se hicieron las búsquedas en bibliotecas, bancos de datos y en sitios de internet. También se realizaron consultas a la Legislación Educativa Brasileña. Concluimos, entonces, que a pesar de diversas conquistas para inclusión de tales contenidos citados en la educación, la lucha por la igualdad afro-brasileña aún no ha terminado.

Palabras-claves: Cultura afro-brasileña; Historia afro-brasileña; Educación.

\section{INTRODUÇÃO}

O ensino de história e cultura afro-brasileira como parte do conteúdo programático, principalmente das aulas de história, de modo a valorizar a contribuição africana para a formação de nosso país, passou a ser assegurado a partir do ano de 1996 pela lei de Diretrizes e Bases da educação. Durante o processo que torna obrigatório a inclusão do conteúdo a ser trabalhado de modo interdisciplinar, foram necessárias à implementação de algumas leis e dos Parâmetros Curriculares Nacionais, que contribuíram para a inclusão do conteúdo nos livros didáticos e para o ensino de tal conteúdo de modo interdisciplinar, incluindo projetos e aperfeiçoamento dos professores em relação a temática.

A contribuição dos africanos para a formação da cultura no Brasil abrange diversas áreas. Na música e na dança destacam-se o samba e a capoeira. Nas influências religiosas temos a Umbanda e o Candomblé. Os principais destaques na culinária são a feijoada, a linguiça e o azeite de dendê. Como exemplo de resistência a situação de suas épocas, destacam-se alguns negros. Dentre esses Chica da Silva, popularmente conhecida como "Cinderela Negra", devido a sua ascensão a burguesia por meio do casamento com um contador de diamantes; Chico Rei, conhecido por sua generosidade e que garantiu aos negros um direito antes exclusivo da burguesia; Dandara dos Palmares, a esposa de Zumbi e conhecida como a heroína dos quilombos; e Zumbi dos Palmares, o herói do quilombo, conhecido por suas habilidades de luta e por sua resistência, morto em 20 de novembro, motivo pelo qual esta data foi escolhida para celebrar o dia Nacional da Consciência Negra.

Um dos principais desafios para trabalhar tal conteúdo em sala de aula é a forma como são tratados os alunos afrodescendentes. Situações de discriminação, preconceito e racismo acontecem com uma frequência maior do que o esperado. Cabe ao professor ter domínio da situação e desconstruir tal preconceito em sala de aula, sendo importante também o apoio da escola para que todos os alunos sejam tratados de mesmo modo, conscientizando a não discriminar ninguém por sua etnia. A luta pela inclusão de tais conteúdos supracitados na educação ainda não acabou. Foram conquistadas diversas vitórias até aqui, mas para garantia de direitos igualitários para estudantes afrodescendentes diversas lutas ainda virão.

A temática foi escolhida para analisar a inclusão do ensino da cultura africana e afro-brasileira nos anos inicias do ensino fundamental. Deste modo, objetivou-se evidenciar a implementação de tal conteúdo em sala de aula, demonstrando de que forma tal cultura está presente e influencia nos costumes brasileiros. Além disso, foi analisada a importância deste ensino para a valorização do negro e a diminuição da prática do racismo em sala de aula.

O presente estudo foi realizado por meio de revisão literária narrativa conceitual, buscando fontes em livros, artigos científicos, dissertação, jornais e revistas, de tal maneira que foram feitas as buscas em bibliotecas, bancos de dados em sites da internet como o SCIELO. Foram utilizadas para a busca as palavras 
chaves: história afro-brasileira, cultura afro-brasileira, ensino fundamental. Além de utilizar materiais que estavam relacionados com: o ensino de história e artes que envolvam a cultura afro-brasileira. Também foram realizadas consultas à Legislação Educacional Brasileira. Os materiais publicados ou registrados foram do período de 1951 a 2017 e o período de realização da pesquisa foi de Janeiro de 2018 a Julho de 2018.

\section{REVISÃO DE LITERATURA}

\section{Inclusão do ensino de história e cultura afro-brasileira}

O ensino da cultura africana sempre fez parte do conteúdo programático das aulas de História, porém o negro era visto apenas como o escravo, sendo desmerecido por esse ponto de vista pejorativo e preconceituoso. Para que esta situação fosse modificada era necessário a implementação de novas diretrizes e bases que levasse a valorização desta cultura (CARVALHO, 2014).

O primeiro passo foi dado através da lei o 9.394 de 20 de dezembro de 1996, também conhecida como lei de diretrizes e bases da educação. Por meio do capítulo segundo são regulamentadas todas as disposições da educação básica, sendo determinado no vigésimo sexto artigo que "O ensino da História do Brasil levará em conta as contribuições das diferentes culturas e etnias para a formação do povo brasileiro, especialmente das matrizes indígena, africana e europeia" (BRASIL, 1996).

Por meio do artigo supracitado, as relações étnicas raciais passam a ser repensadas. Além do estudo da cultura europeia, já fortemente difundido em sala de aula, torna-se obrigatório o ensino da história africana e indígena, integrantes fundamentais da criação dos costumes e tradições do povo brasileiro. Embora seja evidente o papel fundamental do povo africano na cultura de nosso país, a história destes era contada de um ponto de vista preconceituoso, seguindo a linha do racismo (BORGES, 2015).

Em 9 de janeiro de 2003 passou a vigorar a lei no 10.639 que tornou obrigatório o ensino da História e cultura afro-brasileira em todas as escolas, desde o ensino fundamental até o ensino médio. Além disso, tal lei criou o dia da consciência negra, comemorado em 20 de novembro em homenagem a morte de Zumbi dos Palmares (BRASIL, 2003).

Para que a cultura africana fosse estudada de forma igualitária quando comparada as outras, foi necessária a implementação da resolução nำ que entrou em vigor em 17 de junho de 2004. Tal resolução determinava que a temática abordada enfatizasse a importância da contribuição dos africanos e indígenas na construção da História brasileira. Além de promover o aprofundamento de estudos para os professores e incentivar que esses realizassem a criação de projetos relacionados as relações étnicas nas escolas (BORGES, 2015).

A lei citada anteriormente foi alterada em 10 de março de 2008, por meio da lei no 11.645, que incluem a inserção da temática afro-brasileira em todo o currículo escolar, em especial nas disciplinas de Artes, História e Literatura. Seu artigo primeiro determina que

"O conteúdo programático a que se refere este artigo incluirá diversos aspectos da história e da cultura que caracterizam a formação da população brasileira, a partir desses dois grupos étnicos, tais como o estudo da história da África e dos africanos, a luta dos negros e dos povos indígenas no Brasil, a cultura negra e indígena brasileira e o negro e o índio na formação da sociedade nacional, resgatando as suas contribuições nas áreas social, econômica e política, pertinentes à história do Brasil" (BRASIL,2008).

A determinação por meio da lei, para que o conteúdo seja ministrado de forma interdisciplinar e as normas estabelecidas nos Parâmetros Curriculares Nacionais - PCN, estabelecem um grande avanço. Um dos maiores desafios anteriormente era a presença da história e cultura afro-brasileira nos materias didáticos distribuídos para as escolas, onde nem todos apresentavam o conteúdo. De acordo com os novos PCN, os livros didáticos devem ser avaliados por um mesmo padrão, nos sistemas nacional e estadual de educação, garantindo que o conteúdo esteja presente e seja sempre aplicado, mesmo que os métodos de ensino sejam variáveis de acordo com o professor que ministra as aulas (BORGES, 2015). 


\section{Multiculturalismo no Brasil}

O Brasil é internacionalmente conhecido pela sua diversidade cultural. Seu multiculturalismo deriva principalmente da junção de crenças e costumes trazidos por seus colonizadores europeus, pelos escravos africanos e pela população indígena já nativa no pais. Exemplo disso são os costumes específicos de cada região do país, que variam de acordo com aqueles que compõem a maioria da população de cada local. $\mathrm{Na}$ região sul a influência europeia, em maioria alemã e italiana, está presente nas festas tradicionais onde ocorre a pisa da uva, nas danças como o fandango, na culinária desde o vinho, o chimarrão até o barreado. Já na região norte, a tradição indígena prevalece, principalmente na culinária em que estão presentes o tucupi e o tacacá, o jambu e vários pratos onde os ingredientes principais são a base de mandioca e peixe, além é claro das festas típicas como o Festival de Parintins que conta a história do Boi-Bumbá de forma alegre e colorida lembrando as danças das tribos indígenas (FRANCISCO, 2017).

A região centro-oeste tem influências da cultura de alguns estados da região sudeste, do Paraguai e da Argentina e dos índios. Na culinária, várias qualidades de peixes que provem dos rios da região são utilizados, assim como alguns frutos nativos como o pequi. Prevalecem também o arroz carreteiro e a sopa paraguaia, como costumes típicos temos o cururu e o fogaréu. Nas regiões nordeste e sudeste prevalece em grande parte a influência africana, na tradição da congada e na festa de lemanjá, na dança e na música vem o samba, o batuque, o agogô e a luta da capoeira ao som do berimbau. Na culinária, o azeite da palmeira de dendezeiro, trazida da África, é fortemente utilizado, dentre os pratos principais estão o acarajé, o vatapá, a feijoada, o caruru, a farofa e a linguiça. As crenças religiosas, como a Umbanda e o Candomblé, são também de origem afro-brasileira (FRANCISCO, 2017).

A prevalência da cultura africana nas duas regiões citadas anteriormente pode ser facilmente explicada. Durante o período colonial, a maioria dos escravos eram trazidos para região sudeste para trabalhar nas minas e lavouras, mas alguns destes migravam para a região nordeste, principalmente para a Bahia, e após a alforria se mantiveram nessas regiões com suas famílias. Outro fato relevante para esta explicação, era a localização do Quilombo dos Palmares, em Alagoas, para onde fugiam escravos de diversos locais, já que a captura na região era menos propensa devido ao difícil acesso do local (FERREIRA, 2013).

A diversidade das culturas em nosso país também está presente na miscigenação. Durante o período colonial, mais precisamente no século XVII, os africanos trazidos como escravos vinham de diversas regiões do seu país de origem, podendo ser divididos em dois grupos maiores, Bantos e Sudaneses. A hibridização começou pelos descendentes dos próprios africanos e posteriormente pela mistura destes com os europeus. Este fato pode ser explicado por um costume da época, os senhores da elite branca compravam escravas com quem seus filhos tinham a iniciação sexual, e esta, por muitas vezes, resultava em gravidez, da qual os descendentes ficavam conhecidos como mestiços (FERREIRA, 2013). "Da mulata que nos tirou o primeiro bicho- de- pé de uma coceira tão boa. De que nos iniciou no amor físico e nos transmitiu, ao ranger da camade- vento, a primeira sensação completa de homem" (FREYRE, 2001, p. 348).

Outro fator fortemente influenciado pelos afrodescendentes, foi o religioso. Os Bantos trouxeram consigo de seu país os cultos que deram origem ao candomblé de caboclos quando acolhiam os espíritos indígenas, e que posteriormente se transformaram na umbanda. Os feitiços realizados pelos escravos eram famosos, ficaram conhecidos principalmente pelas magias afrodisíacas utilizando de bichos e ervas indígenas, também pelas feitiçarias realizadas com sapos tanto para apressar casamento quanto para acobertar traições das esposas. Já os Sudaneses, em seus cultos uniram as tradições africanas, o catolicismo e o espiritismo, dando origem ao candomblé e a umbanda que até hoje são fortemente praticados (FERREIRA, 2013).

A influência africana teve importantes personalidades, heróis da época, que lutaram por sua liberdade com garra e resistência. Dentre os afrodescendentes mais conhecidos no Brasil, que se tornaram exemplo até os dias atuais podemos destacar Zumbi dos Palmares, Dandara dos Palmares, Chica da Silva e Chico Rei (HERMES, 2017).

Começaremos falando do lendário Zumbi. Nascido no mocambo dos Palmares, em Alagoas, no ano de 1655, era livre até ser capturado no ano de 1662, aos sete anos, e entregue ao padre Antônio Melo pelo qual 
foi batizado com o nome de Francisco. Ficou sob os cuidados do padre, aprendeu latim e português e auxiliava nas missas, até o ano de 1670, quando aos quinze anos de idade fugiu de volta ao quilombo. Suas habilidades na luta e nas artes marciais foram reconhecidas rapidamente, o que Ihe garantiu a fama de bravo guerreiro. Lutou contra soldados portugueses durante ataques ao quilombo, foi contra o atual líder dos Palmares quando o mesmo pretendia um acordo com o coroa portuguesa para que os membros fossem considerados livres, sendo que para Zumbi a liberdade deveria ser para todos os negros (FRAZÃO, 2018).

Por este fato, Zumbi criou uma guerra civil dentro do quilombo, onde derrotou o atual líder e assumiu seu lugar, criando novas normas mais rígidas e beneficiando mais aqueles que ali buscavam abrigo, fato esse que fica comprovado pelo aumento dos membros em quase sete vezes mais entre 1630 a 1678. Domingues Jorge Velho é contratado para liderar uma tropa fortemente armada que destrói o quilombo após uma luta longa, que durou mais de vinte dias. Zumbi, embora devastado por dentro pelo fim do quilombo, ainda consegue fugir por aproximadamente um ano. Foi morto no dia 20 de novembro de 1695, após ter sido capturado, depois da delação de um de seus antigos companheiros, teve a cabeça decepada e exposta na praça pública em Recife. Devido a este fato, como forma de homenageá-lo foi instituído no Brasil, em 2003, o dia Nacional da Consciência Negra, comemorado em 20 de novembro. Foi o principal exemplo de herói negro, por sua resistência e por sua luta pela igualdade racial e o fim da escravidão (FRAZÃO, 2018).

Dandara foi esposa de Zumbi, viveu no Quilombo dos Palmares, foi exemplo de luta e determinação. Exerceu os mais variados tipos de atividades, deste de plantação, caça, serviços domésticos, até a luta e empunhadura de armas. Foi capturada e em forma de resistência, para não ser escravizada, jogou-se de uma pedreira, cometendo o suicídio em 6 de fevereiro de 1694. Por todos esses fatos citados é considerada a heroína do quilombo (TINOCO, 2014).

Francisca da Silva de Oliveira, mais conhecida por Chica da Silva, nasceu em Diamantina no ano de 1732, era filha de um português e uma africana. Foi livre até a adolescência e depois foi comprada pelo sargentomor Manoel Pires Sardinha para trabalhar em suas lavouras, com ele teve um filho em 1751, Simão Pires Sardinha, e este foi reconhecido como herdeiro legitimo do pai. Em 1753, com vinte e dois anos de idade, foi comprada pelo contador de diamantes João Fernandes de Oliveira, em pouco tempo foi alforriada e passou a viver com ele. A união com o contador durou dezessete anos e frutos dessa relação vieram treze filhos. Todos os herdeiros receberam o sobrenome do pai e tiveram acesso a uma educação excelente. $O$ contador precisou retornar a Portugal após a morte de seu pai em 1770, foi levando seus filhos homens como era costume na época, deixando Chica e as filhas em Minas Gerais (FRAZÃO,2016).

João Fernandes não retornou de Portugal e então Chica da Silva assumiu a educação das filhas e os negócios do marido. Embora não tenha vivido com o contador, que faleceu em 1779, o restante dos anos de sua vida, continuou sendo respeitada pela elite mineira. Fez doações as igrejas da região, tanto para as exclusivamente da elite branca, quanto a dos mestiços e a dos negros. Faleceu no dia 15 de fevereiro do ano de 1796 e indo contra os costumes da época seu sepultamento foi realizado em um local até então exclusivo dos brancos, mais precisamente na então irmandade religiosa São Francisco de Assis. Chica foi exemplo por suas conquistas, ficou popularmente conhecida como "Cinderela negra" graças a sua ascensão a elite, até então exclusiva dos brancos, por meio da sua união estável com o contador. Em contrapartida, podemos levantar a hipótese de que ela por si só conquistou seu lugar junto a classe burguesa da região, já que mesmo na ausência de seu cônjuge, seu posto foi mantido (BERNARDO, 2016).

Chico Rei, como ficou conhecido devido sua generosidade, antes de batizado Francisco era chamado pelo nome de Galanga. Veio para o Brasil em um navio em 1739, foi vendido junto a sua esposa para trabalhar na Mina da Encardideira, em Ouro Preto. Trabalhou, incansavelmente, até conseguir comprar sua liberdade e de sua mulher. Foi exemplo de solidariedade quando comprou também a alforria daqueles que vieram junto a ele no navio. Era devoto de Nossa Senhora do Rosário dos pretos e de Santa Efigênia, em 1785 construiu junto a outros negros uma igreja dedicada as santas. Esta construção foi um grande marco para os negros por dois motivos principais, primeiro por possibilitar que os corpos destes fossem sepultados dignamente em um cemitério católico, o que antes só era permitido aos brancos, e segundo permitiu que manifestassem sua fé com cantos, danças e louvores as santas (WERNECK, 2012). 


\section{Valorização das diversidades}

A inclusão do estudo da História e cultura afro-brasileira tem importância significativa na desconstrução do preconceito étnico e racial. O professor tem papel fundamental neste processo, pois a forma como esse aborda a temática e lida com as perguntas confrontantes de seus alunos influi na visão dos mesmos sobre a diversidade cultural (SILVA E FONSECA, 2007). "Exige dos professores sensibilidade, postura crítica e reflexão sobre nossas ações, sobre o cotidiano escolar, sobre as relações sociais e culturais que experienciamos no século XXI" (BORGES, 2015, p.12).

A resolução que implementou as Diretrizes Curriculares Nacionais para a Educação das Relações Étnico Raciais e para o Ensino de História e Cultura Afro-Brasileira e Africana, determina em seu artigo primeiro que as instituições de ensino devem estar capacitadas para trabalhar tal temática, principalmente aquelas que tem por papel a formação dos professores, já que estes devem estar visivelmente preparados para abordar este assunto em sala de aula. As mesmas diretrizes por meio de seu artigo terceiro determinam que as instituições de ensino são responsáveis por estabelecer a forma de que a temática deve ser trabalhada, por meio de atitudes e valores, transmitidos por meio dos professores e com apoio e supervisão do sistema de ensino (BRASIL, 2004)

"A atual política curricular atribui ao ensino o papel de formar um novo cidadão, capaz de compreender a história do país e do mundo como resultante de múltiplas memórias originárias da diversidade de experiências humanas em oposição ao entendimento, até então dominante, de uma memória unívoca das elites ou de um passado homogêneo" (BORGES, 2015, p. 12).

O artigo quinto das diretrizes estipula que o professor, além de estar capacitado para ministrar o conteúdo, deve estar preparado para assegurar ao aluno negro os seus direitos e corrigir aqueles que manifestem palavras de desrespeito e discriminação no ambiente escolar. Por meio desse fica claro que além de transmitir os ensinamentos sobre a cultura afro-brasileira é fundamental garantir os direitos dos afrodescendentes e quebrar o preconceito existente. (BRASIL, 2004)

Para melhor compreensão da questão vamos definir as diferenças entre racismo, preconceito e discriminação. Racismo é uma relação de hostilidade a diferentes raças e etnias, considerando a supremacia de apenas uma etnia sobre as demais. Já o preconceito é uma ideia criada sobre determinado assunto antes de conhece-lo, normalmente associada a aquilo que outras pessoas pensam sobre o assunto, que geralmente leva a intolerância. E, por fim, a discriminação pode ser definida com a quebra da equidade, diferenciação e exclusão de um determinado grupo. Outro fator relevante é determinar também os significados de cor, raça e etnia. Cor é a pigmentação presente na pele, raça é a subdivisão de espécies que apresentam características obrigatoriamente herdadas por todos seus descendentes, no caso da espécie humano existe apenas uma raça, e etnia pode ser definida como um conjunto de características presentes no indivíduo de cada região, dentre esses, o modo de falar, a crença religiosa e suas formas de agir e se vestir (ANDREUCCI, 2016).

Para garantir igualdade aos afrodescendentes, em 3 de julho de 1951 passou a vigorar a lei ํㅡ 1.390, conhecida como Lei de Afonso Arinos, que determinava penalizações para aqueles que praticassem 0 preconceito de raça e cor. As penas variavam de multas no valor de 500 a 5000 cruzeiros, prisão simples de quinze dias a um ano e em alguns casos específicos a perda do cargo exercido pelo agressor (BRASIL, 1951).

A lei citada anteriormente foi modificada pela o 7.716 que entrou em vigor em 5 de janeiro de 1989, onde além do preconceito de raça e cor também incluía o preconceito a etnias. As principais modificações realizadas foram em relação a penalidades, cuja reclusão de (no máximo) um ano passa a ser de até cinco anos. Por fim, para concluir as modificações necessárias, em 20 de julho de 2010 foi instituído o Estatuto de Igualdades Raciais, por meio da lei ํㅜ 12.288 que passou a garantir para os afrodescendentes a efetivação da igualdade de oportunidades, a defesa dos direitos étnicos individuais, coletivos e difusos e o combate à discriminação e às demais formas de intolerância étnica (BRASIL, 2010). 


\section{CONSIDERAÇÕES FINAIS}

Para que a cultura e história afro-brasileira fosse ganhando espaço entre os conteúdos estudados, principalmente nas aulas de História, foram necessários anos de lutas. A implementação de leis foi fundamental neste processo, pois através delas foram promovidos estudos para o aprofundamento de tal temática pelos professores e incentivada a implementação de projetos escolares de modo que a participação africana no desenvolvimento do Brasil fosse valorizada e reconhecida. Tal participação contribuiu na formação de estilos musicais, na dança, nas crenças religiosas e, principalmente, na culinária.

Alguns negros ainda se destacaram na história do país por serem exemplo de luta e resistência para alcançarem direitos iguais para aqueles de sua mesma etinia, dentre esses, Chica da Silva, Chico Rei, Dandara dos Palmares e, por fim, Zumbi dos Palmares conhecido por sua bravura e aquele que ganhou como homenagem pelo dia de sua morte a instituição do dia Nacional da Consciência Negra em tal data. Para que o aluno afrodescendente tenha seus direitos assegurados em ambiente escolar é necessário que o professor esteja preparado para lidar com diversos desafios, dentre esses destacando-se o racismo, o preconceito e a discriminação.

Sendo assim, concluímos que a luta pela inclusão de tais conteúdos supracitados na educação ainda não acabou. Foram conquistadas diversas vitórias até aqui mas, para o estudo do conteúdo de forma igualitária são necessárias postura do professor e apoio da escola para que, deste modo, o aluno negro não seja hostilizado pelas diversas formas de discriminação e possa ser tratado de forma digna e igualitária, ou seja, como os outros estudantes ali presentes.

\section{REFERÊNCIAS BIBLIOGRÁFICAS}

1. ANDREUCCI, Ricardo Antonio. Preconceito, Discriminação e Intolerância no Brasil. $2016 . \quad$ Disponível em: <http://emporiododireito.com.br/leitura/preconceito-discriminacao-e-intolerancia-no-brasil-por-ricardo-antonio-andreucci>. Acesso em: 26 fev. 2018.

2. BERNARDO, André. 'A escrava que virou rainha': documentário e livros revivem história da brasileira que rompeu padrões do século 18.2016 . Disponível em: https://www.bbc.com/portuquese/geral-36658302. Acesso em: 26 mar. 2018.

3. BORGES, Elisabeth Maria de Fátima. INCLUSÃO DA HISTÓRIA E DA CULTURA AFROBRASILEIRA E INDíGENA NOS CURRíCULOS DA EDUCAÇÃO BÁSICA E SUPERIOR: momento histórico ímpar. 2015. 14 f. Dissertação (Mestrado) - Curso de História, Universidade Federal de Goiás, Goiânia, 2015.

4. BRASIL. Lei ํㅜ 1390, de 03 de julho de 1951. Inclui entre as contravenções penais a prática de atos resultantes de preconceitos de raça ou de côr.. Rio de Janeiro, RJ,

5. BRASIL. Lei no 7.716 , de 05 de janeiro de 1989. Define os crimes resultantes de preconceito de raça ou de cor. Brasilia, DF.

6. BRASIL. Lei no 9394, de 20 de dezembro de 1996. Estabelece as diretrizes e bases da educação nacional. Brasilia, DF.

7. BRASIL. Lei no 10.639 , de 09 de janeiro de 2003. Altera a Lei no 9.394, de 20 de dezembro de 1996, que estabelece as diretrizes e bases da educação nacional, para incluir no currículo oficial da Rede de Ensino a obrigatoriedade da temática "História e Cultura Afro-Brasileira", e dá outras providências. Brasilia, DF.

8. BRASIL. Resolução no 1, de 17 de junho de 2004. Institui Diretrizes Curriculares Nacionais para a Educação das Relações Étnico Raciais e para o Ensino de História e Cultura Afro-Brasileira e Africana. Brasilia, DF.

9. BRASIL. Lei no 11645 , de 10 de março de 2008. Altera a Lei no 9.394, de 20 de dezembro de 1996, modificada pela Lei no 10.639, de 9 de janeiro de 2003, que estabelece as diretrizes e bases da educação nacional, para incluir no currículo oficial da rede de ensino a obrigatoriedade da temática "História e Cultura Afro-Brasileira e Indígena". Brasilia, DF.

10. BRASIL. Lei $n^{0} 12.288$, de 20 de outubro de 2010. Institui o Estatuto da Igualdade Racial; altera as Leis nos 7.716 , de 5 de janeiro de 1989 , 9.029 , de 13 de abril de 1995, 7.347, de 24 de julho de 1985, e 10.778, de 24 de novembro de 2003. Brasilia, DF.

11. CARVALHO, Leandro. LEI 10.639/03 E O ENSINO DA HISTÓRIA E CULTURA AFRO-BRASILEIRA E AFRICANA. 2014. Disponível em: https://educador.brasilescola.uol.com.br/estrategias-ensino/lei-10639-03-ensino-historia-cultura-afro-brasileira-africana.htm . Acesso em: 21 mar. 2018.

12. FERREIRA, Márcio Carvalho C. A influência africana no processo de formação da cultura afro-brasileira. 2013 . Disponível em: <http://www.acordacultura.org.br/artigos/29082013/a-influencia-africana-no-processo-de-formacao-da-cultura-afro-brasileira>. Acesso em: 19 abr. 2018.

13. FRANCISCO, Wagner de Cerqueira e. Diversidade cultural no Brasil. 2017. Disponível em: https://brasilescola.uol.com.br/brasil/a-diversidadecultural-no-brasil.htm . Acesso em: 12 mar. 2018.

14. FRAZÃO, Dilva. Chica da Silva: Escrava brasileira alforriada. 2016. Disponível em: <https://www.ebiografia.com/chica_da_silva/>. Acesso em: 13 abr. 2018.

15. FRAZÃO, Dilva. Zumbi dos Palmares: Líder da resistência negra. 2018. Disponível em: <https://www.ebiografia.com/zumbi/>. Acesso em: 16 abr. 2018.

16. FREYRE, Gilberto. Casa-grande \& Senzala. Rio de Janeiro: Record, 2001.

17. HERMES, Felippe. 7 personagens negros da história do Brasil mais importantes que Zumbi (e que você deveria conhecer). 2017. Disponível em: https://spotniks.com/7-personagens-negros-da-historia-do-brasil-mais-importantes-que-zumbi-e-que-voce-deveria-conhecer/ . Acesso em: 16 mar. 2018.

18. SILVA, Marcos; FONSECA, Selva. Ensinar e aprender História no século XXI: em busca do tempo perdido. Campinas: Pairus, 2007.

19. TINOCO, Dandara. Descrita como heroína, Dandara, mulher de Zumbi, tem biografia cercada de incertezas. 2014 . Disponível em: https://oglobo.globo.com/sociedade/historia/descrita-como-heroina-dandara-mulher-de-zumbi-tem-biografia-cercada-de-incertezas-14567996 . Acesso em: 25 mar. 2018.

20. WERNECK, Gustavo. Conheça a nobreza de Chico Rei em Ouro Preto. $2012 . \quad$ Disponível em: https://www.em.com.br/app/noticia/gerais/2012/10/20/interna gerais,324537/conheca-a-nobreza-de-chico-rei-em-ouro-preto.shtml . Acesso em: 14 abr. 2018. 